\title{
IMIGRAÇÃO: AS VERDADES REVELADAS PELA \\ PANDEMIA E OS GARGALOS ESTRUTURAIS DE ACESSO A DIREITOS NA CIDADE DE SÃO PAULO*
}

Patrícia Villen

Sávia Cordeiro

\section{Introdução}

Sayad nos lembra que são os momentos de crise, marcados pelo desemprego e pelo acirramento de conflitos sociais, que fazem a "verdade da imigração" emergir, evidenciando a "condição de provisoriedade permanente" do imigrante. Essa condição é reafirmada quando os Estados provocam o refluxo desses imigrantes e, sobretudo, quando operam a ainda mais acentuada espoliação de seus direitos durante as crises. Isso, porque para os Estados o imigrante só tem sentido de existir quando as vantagens da sua presença superam os custos. A condição de trabalhador tolerado a título provisório coloca-nos, portanto, a essência da condição do imigrante: uma força de trabalho "provisória", "temporária”, "em trânsito", "revogável a qualquer momento" (SAYAD, 1998: 54). Como nos ensina o autor, "exportam-se ou importam-se exclusivamente trabalhadores, mas nunca cidadãos atuais ou futuros. Essa é a condição necessária para que existam emigração e imigração. É uma exigência da ordem simbólica” (SAYAD, 1998: 55).

Tinha razão Sayad. O contexto da pandemia causada pelo novo Coronavírus é revelador de muitas verdades sobre a imigração. Essas verdades nos ajudam a entender por que cenas e situações parecidas em geral muito problemáticas, para não dizer trágicas - se repetem em diferentes partes do globo para imigrantes e refugiados ${ }^{1}$.

${ }^{*}$ DOI - 10.29388/978-65-86678-07-9-0-f.65-82 
Na imbricação de uma crise sanitária com uma econômica, a supramencionada condição de provisoriedade está se revelando, em nível mundial, sem nenhum pudor em relação ao imigrante. Para os Estados, na pandemia, quando a força de trabalho do imigrante deixa de ter utilidade, parece que o melhor a ser feito é expeli-lo o quanto antes. Mas, quando isso não é possível, basta situá-lo no sonhado lugar da inferioridade material, simbólica e jurídica, que acompanha a expectativa de submissão incondicional do imigrante a essa condição, lembrando-o de ser um estrangeiro e não ter os mesmos direitos dos nacionais.

\section{As verdades da imigração reveladas pela pandemia}

Uma das verdades reveladas pela atual crise diz respeito à gestão da força de trabalho do imigrante pelos Estados a partir da premissa da temporalidade. Trata-se do sistema de migração temporário, também chamado de circular migration (CONSTANT et al., 2011), que mobiliza milhares de trabalhadores sazonais ao redor do mundo. Estes são contratados em regime temporário, na condição de hóspedes no país de destino - recebendo diferentes denominações para ressaltar esse caráter provisório, como, por exemplo, gastarbeiter ou bird of passage. Esses trabalhadores temporários, ao entenderem que não po-

\footnotetext{
${ }^{1}$ Para os refugiados, pessoas que deixam seus países por se encontrarem em situação de risco, portanto que têm uma necessidade extrema de serem acolhidos por outro Estado, a COVID-19 serviu como grande álibi para a suspensão do direito de refúgio, que nas últimas décadas já tem sido extremamente negligenciado. É como se essas pessoas pudessem esperar para pedir seu direito de refúgio. Assim, foram sus pendidos os serviços de socorro aos conhecidos barcos lotados de homens, mulheres e crianças que tentam atravessar o Mediterrâneo para chegar à Europa. Para os refugiados que vivem nos campos de refúgio ou em abrigos para refugiados, a solução encontrada foi a de reforçar as fronteiras dessas localidades, impedindo a circulação dessas pessoas nas cidades, ou seja, impondo o isolamento já operante, porém de forma ainda mais violenta e restrita. A verdade é que por serem refugiados, não têm o direito de frequentar os hospitais como os outros cidadãos e, sobretudo, em nenhuma hipótese devem circular para além das fronteiras de seus campos ou abrigos para evitar o contágio dos cidadãos (leia-se, dos nacionais). Para a situação dos refugiados, ver Villen (2020).
} 
deriam mais trabalhar e que ficariam, portanto, sem renda, como seria de se esperar, desejaram voltar para casa. Todavia, esse desejo não pôde ser realizado para muitos deles, que ficaram dias bloqueados nos aeroportos de diferentes cidades do mundo sem ter o que comer, nem onde dormir, como foi o caso dos trabalhadores colombianos em Cumbica, Guarulhos-SP (MONTOVANI; FRAISSAT, 2020).

Para os imigrantes sazonais sem acesso aos aeroportos, o tratamento recebido foi ainda pior, como é o caso de duzentos chilenos que foram detidos em um campo militar na Bolívia, ficando impedidos de se locomoverem (VILLARREAL, 2020). No Oriente Médio, os números de trabalhadores imigrantes sazonais enclausurados em campos são ainda mais impressionantes. No Kwait, por exemplo, mais de vinte mil imigrantes ficaram presos em campos de detenção em condições precárias e altamente propícias à propagação do Coronavírus (ULLAH, 2020). Nesse quadro, os abusos dos empresários das fronteiras, explorando o desespero do imigrante, também estão plenamente ativos, como foi o caso dos marroquinos que pagaram cerca de $\mathrm{R} \$ 33.000$ para conseguirem voltar para seu país, que havia fechado suas fronteiras para os próprios nacionais (MARTIN, 2020).

A quantidade exorbitante de trabalhadores imigrantes e refugiados que vive em situação indocumentada foi outra verdade revelada pela pandemia. Muitos Estados aproveitaram o regime de emergência da pandemia para expulsar os imigrantes indocumentados, como é o caso dos Estados Unidos de Trump, do México e do Peru, que rapidamente aprovou uma lei permitindo essas deportações em massa. Em particular, o que mais pareceu conveniente para os Estados foi a determinação de que a situação irregular impede o acesso a direitos sociais, sejam de tratamento de saúde, sejam de assistência social ${ }^{2}$. Países como a Itália - que possui uma expressiva população de emigrantes e também de imigrantes - se encontrou diante do dilema de não querer beneficiar os imigrantes indocumentados, porém, ao mesmo tempo,

\footnotetext{
${ }^{2} \mathrm{O}$ caso de Portugal que optou excepcionalmente pela regularização das milhares de imigrantes indocumentados que vivem naquele país, para que pudessem ser identificados e tratados adequadamente no contexto da pandemia, representa uma exceção.
} 
cobrar dos outros Estados - onde sua população emigrante reside um suporte ao conacionais que se encontraram do dia para a noite sem emprego e renda. Conforme explicam Lanza et al. (2018), a nova lei de migração no $13.445 / 2017$, assegurada pela Constituição Federal (1988) em vigor, não permite a discriminação dos imigrantes (documentados e indocumentados) e dos refugiados (dos solicitantes de refúgio ou dos refugiados reconhecidos) para o acesso aos serviços públicos de educação e saúde, à assistência social e aos direitos sociais ou seja, no Brasil a legislação reconhece aos estrangeiros os mesmos direitos dos brasileiros. No entanto, conforme destacam as autoras, essa garantia formal já apresentava muitas barreiras para ser efetivada na prática. No contexto da pandemia, como será evidenciado em seguida, essas barreiras também se fazem presente com efeitos muito graves para esse grupo social.

Essa aberração humanitária de negar ajuda aos indocumentados provocou muitas campanhas, com a bandeira "regularize já", de movimentos sociais e de entidades representantes dos imigrantes. Tais campanhas se disseminaram em diversos países, mostrando que apenas o reconhecimento da presença dessas pessoas invisíveis poderia significar uma medida eficaz para impedir as mazelas da pandemia.

No Brasil, diversas organizações, pesquisadores e ativistas já demonstraram apoio a essa campanha, que, como já mencionado se trata de uma demanda política presente em diferentes países, já que, nos últimos anos, houve uma explosão do número de imigrantes /refugiados que vivem em situação indocumentada, devido às políticas e leis restritivas da imigração, o aumento do controle e militarização das fronteiras. Segundo Basso e Perocco (2003: 22 e 23), trata-se de uma "produção global da clandestinidade" que "é tudo menos involuntária" por parte dos Estados e instituições.

Essa reivindicação também se mostra pertinente no Brasil, tendo em vista os efeitos práticos nocivos, no trabalho e na vida cotidiana, que a situação indocumentada provoca para muitos imigrantes e refugiados que vivem no nosso país. No que se refere ao atual contexto de 
pandemia, essa demanda também responde a uma pressão dos imigrantes em meio à suspensão das atividades da Polícia Federal, no que tange à regularização migratória. Entretanto, do ponto de vista normativo, é importante ressaltar que a construção jurídica da nova lei de migração brasileira possui um horizonte de alcance mais ambicioso, qual seja, o acesso a serviços públicos e a garantia dos direitos da população imigrante, independente da condição migratória.

Não poderíamos nos esquecer de outra importante verdade revelada - associada às anteriores -, a vulnerabilidade socioeconômica do imigrante. "Diante da crise de COVID-19, todos somos vulneráveis. $\mathrm{O}$ vírus mostrou que não discrimina - mas muitos refugiados, deslocados à força, apátridas e migrantes estão em maior risco.” Este comunicado feito no dia 31 de março de 2020, pelo Escritório do Alto Comissariado das Nações Unidas para os Direitos Humanos (ACNUDH), pela Organização Internacional para as Migrações (OIM), pela Agência da ONU para Refugiados (ACNUR) e pela Organização Mundial da Saúde (OMS), chama atenção para maior vulnerabilidade da população imigrante aos efeitos da pandemia do coronavírus, em razão da discriminação, da falta de acesso a serviços públicos e pela dificuldade de integração econômica, o que os coloca em condições de trabalho altamente precarizadas.

Como essas pessoas são por excelência as candidatas aos piores empregos, em regimes precários, flexíveis, temporários, intermitentes - que Basso (2013) chamou de protótipo do trabalhador flexível - elas também ficaram rapidamente expostas às diversas imposições do sistema para quem depende absolutamente do trabalho ou de uma pequena renda para sobreviver. Essas pressões já são difíceis de se suportar em tempos econômicos normais e ficaram ainda mais pesadas por causa da paralisação das atividades, em função da pandemia. Casos de desemprego, de fome, de despejos indiscriminados, de situação de rua, de maior exposição a exploração e abusos, de tráfico de humanos se multiplicaram para esse grupo social, em diferentes partes do globo. Países que são particularmente marcados pela emigração, como Bir- 
mânia, Indonésia, Bangladesh, Vietnam, Myanmar se deparam com a emergência de verem sua população obrigada a retornar por se encontrar sem trabalho, sem proteção social e sem rede de apoio nos países de destino, quando não sendo expulsa desses lugares. O futuro que essas populações encontrarão em seus países, sobretudo devido à crise econômica, também é bastante incerto. A indústria global da moda, que opera há anos nessa região, lucrando em cima desses trabalhadores, se recusa a continuar pagando o conhecido salário de fome para seus funcionários, grande parte deles trabalhadores imigrantes.

Do mesmo modo, se multiplicaram casos de violência (física e psicológica), racismo e xenofobia contra esse grupo social. Trata-se, como nos ensina Basso (2010), de um Racismo de Estado, que é fomentado "por cima" e que nas últimas décadas vem se caracterizando por um "salto de qualidade". $\mathrm{O}$ ataque às Torres Gêmeas, em 11 de setembro de 2001, significou um marco histórico para entendermos esse salto de qualidade na atuação do racismo de Estado. A atual pandemia, indubitavelmente, significará outro. Trata-se de uma arma antiga dos Estados, mas que nos contextos de crise se torna um instrumento imprescindível de governo, colocando os "estrangeiros" como bodes expiatórios dos problemas enfrentados pelos nacionais. Por esse motivo, na pandemia, uma das primeiras providências tomadas pelos Estados foi o "fechamento" (seletivo) das fronteiras e sua ainda mais acentuada militarização. Longe de os Estados procurarem uma cooperação global contra a pandemia, as fronteiras foram se fechando seletivamente como pretensa solução para pandemia.

Concomitantemente, serve também aos Estados a arma do nacionalismo - e seu veneno - para dividir as populações, particularmente a classe trabalhadora. Mesmo no Brasil, que tem uma porcentagem baixíssima de imigrantes em relação aos países do Norte Global, o Racismo de Estado serve de álibi ao governo. São conhecidas as manifestações do presidente Bolsonaro em relação aos imigrantes e refugiados, segundo ele, "a escória do mundo" (AZEVEDO, 2015). Ora, a primeira fronteira fechada no Brasil foi com a Venezuela, junto com as 
embaixadas em ambos os países. Isso quer dizer que os emigrantes brasileiros ficaram sem ter onde recorrer na Venezuela e igualmente os milhares de venezuelanos que estão no Brasil. Não por acaso, os venezuelanos, além de serem a nacionalidade mais afetada em relação a questões socioeconômicas na América Latina, têm sido vítima, no Brasil, de diferentes ataques de extrema violência, sobretudo no Norte do país, pela população brasileira que se sente "ameaçada". Mais grave, a verdade é que esses casos de violência contra imigrantes são generalizados no país inteiro - atingindo principalmente os imigrantes e refugiados negros de origem africana ou haitiana. Se já estavam ocorrendo no contexto de crise econômica, particularmente após 2014, agora tendem a se multiplicar.

No entanto, em meio a essas verdades, há uma mais latente, escondida, que é a necessidade estrutural, portanto contínua, mesmo na pandemia, de trabalhadores imigrantes. A presença do trabalho imigrante nos diferentes países, sobretudo do Norte Global, é vital para permitir o funcionamento da economia, em especial para alguns setores como o trabalho doméstico e de cuidado, limpeza, construção civil, agricultura, serviços em geral. Essa verdade gerou uma grande polêmica, por exemplo, na Itália, que se deparou - após ter aprovado a lei draconiana contra imigrantes e refugiados chamada Lei Segurança e Imigração (2018) - com a necessidade de decidir o que fazer para que as plantações agrícolas e as famílias que utilizam o trabalho de cuidado das mulheres imigrantes pudessem continuar contando com essa força de trabalho, em grande parte indocumentada. Esse mesmo dilema se repetiu nos diferentes cantos do globo para evitar que diversos setores ficassem sem funcionar devido à falta de trabalhadores imigrantes. De outro lado, é preciso lembrar que a tentativa de entrar no Norte Global pelos imigrantes indocumentados não para nem mesmo durante a pandemia (Martin, 2020).

Há também a trágica verdade sobre a indiferença em relação à morte das populações deslocadas ou em deslocamento. $\mathrm{O}$ caso dos refugiados é certamente o mais alarmante, já que os campos de refúgio 
que abrigam milhares de pessoas proibidas de circularem fora dessa zona, além de terem grande densidade populacional, não possuem hospitais com estrutura para tratar os contagiados pela COVID-19. Para aqueles que se encontram em trânsito, o drama é ainda maior, pois agora os Estados têm mais um motivo para se recusarem a receber ou prestar ajuda, como é o caso dos navios cheios de refugiados que atravessam cotidianamente o Mediterrâneo e, durante a pandemia, ficaram sem nenhum sistema de socorro. A proibição da solidariedade e de iniciativas de ajuda a esses refugiados agora está legitimada no contexto da pandemia. Em algumas regiões com mais imigrantes e refugiados, como nas cidades com maior concentração de hispânicos e brasileiros dos EUA, há 30\% mais mortes pela COVID-19 do que em outros lugares (SANCHES, 2020).

Por fim, a divisão internacional do trabalho e a correlata hierarquia das nações e das nacionalidades, característica de funcionamento do sistema de imigração (SAYAD, 1998), também merecem destaque enquanto verdade da imigração revelada pela pandemia. A maior parte da população deslocada hoje é proveniente de países periféricos. Se antes da COVID-19, o retorno para casa já era algo problemático, para não dizer inviável para muitos desses imigrantes e refugiados, agora, com a crise econômica que se acirra na pandemia, seus países de origem serão ainda mais assolados pelos diferentes tipos de devastação econômica. Isso quer dizer que ainda mais pessoas serão obrigadas a migrar no futuro para sobreviverem, fugirem dos problemas estruturais típicos da periferia do capitalismo, buscando melhorar suas condições de vida.

Embora esses países sejam predominantemente produtores de emigrantes, é preciso lembrar que também são territórios de trânsito e de imigração. Sem dúvida alguma, será ainda maior o choque para os imigrantes periféricos - os periféricos na periferia - que migram para países da periferia do sistema (a chamada migração Sul-Sul), sonhando em deixar para trás esses problemas (trabalho, falta de acesso a direitos sociais, racismo, falta de moradia, entre outros). A desilusão de 
se encontrar novamente em um país que se mostra também marcado por esses problemas estruturais agora será ainda mais perversa. Essa desilusão passa pela compreensão de que os próprios nacionais, ou seja, a classe trabalhadora desses países também está sendo duramente atingida por esses problemas.

O Brasil é um dos países da periferia do capitalismo onde essa desilusão, se já não existia, certamente se colocará a esse grupo social, que sente na pele o que é estar em terras estrangeiras em um contexto de grave crise sanitária, econômica, política e também civilizacional. A dificuldade que o Estado brasileiro tem de reconhecer ${ }^{3}$ a "nova" imigração proveniente do Sul global - os "invisíveis globais" (VILLEN, 2018) - como parte da sua história da imigração e como parte da sua população permanente, como será analisado a seguir, a partir do caso da cidade de São Paulo, se revela nos "gargalos estruturais" para garantia de acesso a direitos para essa população com efeitos agravados pela pandemia.

A cidade de São Paulo, território com maior concentração de imigrantes e refugiados do Brasil e também área de atuação do Centro de Referência e Atendimento para Imigrantes (CRAI/SP) é um espaço privilegiado para entendermos as demandas e os impactos para população imigrante da Covid-19 e também os desafios colocados a nossa sociedade e instituições para garantir o acesso a direitos para esse grupo social.

\footnotetext{
${ }^{3}$ Essa invisibilidade desejada ficou escancarada na não inclusão do item nacionalidade nos formulários sobre a Covid-19 e SRAG, que impede a contabilização de "es trangeiros" contaminados e mortos pelo coronavírus Por esse motivo, a Rede de Cuidados em Saúde para Imigrantes iniciou uma campanha para "combater a invisibilidade de imigrantes e refugiados" como "medida urgente para garantir o direito à saúde" desse grupo social.
} 


\section{Demandas da população imigrante e os gargalos estruturais para garantia de acesso a direitos}

No cenário nacional, destacam-se algumas normativas principais que afetaram a população imigrante no início da pandemia. Em primeiro lugar, está a Lei 13.979, de 6 de fevereiro de 2020, que dispõe sobre as medidas de enfrentamento de emergência de saúde pública, em razão do surto de coronavírus. Além disso, ressalta-se a medida provisória no 926 de 20 de março de 2020, que permite a restrição excepcional e temporária de entrada e saída do país por rodovias, portos e aeroportos. Em decorrência, a Polícia Federal, por meio de normativa interna, suspendeu todos os atendimentos de regularização migratória assim como os prazos correspondentes a partir de 16 de março de 2020. Considerou também prorrogados os prazos de vencimento de protocolos, carteiras e outros documentos relativos às atividades de regularização migratória, incluindo certidões para instruir os procedimentos. Por fim, salienta-se o decreto 10.312, de 7 de abril de 2020, que apresenta as medidas de proteção social, incluindo o auxílio emergencial.

Cada Estado e município tem tomado suas próprias providências em relação às medidas de combate ao coronavírus a partir de uma combinação preocupante de ideologias políticas, recomendações científicas e pressões econômicas. Neste artigo, são apresentadas as ações feitas pelo município de São Paulo, por ser a área de atuação do Centro de Referência e Atendimento para Imigrantes (CRAI/SP). Em virtude do decreto federal 10.282/2020, que dispõe sobre os serviços essenciais que devem permanecer abertos durante a pandemia, a Prefeitura de São Paulo declarou, por meio do decreto 59.283 de 16 de março de 2020, a situação de emergência no município de São Paulo. Em decorrência, a Secretaria Municipal de Direitos Humanos e Cidadania considerou que o serviço especializado de atendimento à população imigrante (CRAI/SP) se enquadraria dentro da categoria de serviços essenciais, com o objetivo de orientar e prestar apoio a essa população 
sobre as medidas de prevenção ao coronavírus e para garantir o acesso aos serviços públicos municipais no período de pandemia.

Outra orientação importante foi a nota técnica n 01/SMADS/ 2020 da Secretaria Municipal de Assistência Social e Desenvolvimento Social. Voltada aos serviços da rede socioassistencial, esta orientação foi bastante aguardada pela rede de atenção ao migrante, em razão, principalmente, do funcionamento dos centros de acolhida específicos para imigrantes no município e para esclarecimento do fluxo de atendimento para conviventes que apresentassem sintomas de COVID-19. Em face de um cenário prévio de desmonte de políticas sociais, que tem afetado diretamente a oferta de serviços socioassistenciais na rede municipal, em especial na região central da cidade, a preocupação sobre uma possível sobrecarga dos serviços de acolhimento no período de pandemia e a falta de oferta de vagas para a população imigrante se mostra completamente pertinente.

No período de 19 de março a 28 de abril de 2020, o CRAI/SP realizou 365 atendimentos. Foram 39 nacionalidades atendidas, com um número mais expressivo de imigrantes venezuelanos. Houve um leve aumento na faixa etária do público atendido, por número maior de atendimento a pessoas idosas. Por outro lado, permaneceu inalterada a maior proporção de atendidos do gênero masculino do que feminino.

Destacam-se três principais demandas nesse período por parte da população imigrante. Em primeiro lugar, a demanda de acolhimento foi expressiva nas primeiras semanas de isolamento social. O processo de interiorização da comunidade venezuelana continua em meio à pandemia, e verifica-se uma constância no número de famílias recém-chegadas a São Paulo, provenientes de Estados do norte do país. Além disso, houve um aumento de solicitações de Consulados que buscam apoio aos seus nacionais desabrigados.

Com o início do cadastramento para auxílio emergencial, aumentaram as demandas relacionadas à inscrição ou alteração cadastral do CPF, com o objetivo de regularizá-lo para solicitação de auxílio. No 
momento, o atendimento na Receita Federal se dá apenas de forma online, por email. Isso dificulta o acesso de populações vulneráveis, entre elas, os imigrantes. O CRAI/SP serviu de apoio e encaminhou solicitações de inscrição e alteração cadastral, porém, em muitos casos, o tempo de resposta se mostra irrazoável, levando dias ou até semanas.

Para além disso, o procedimento para solicitação de auxílio emergencial por si só tem sido uma demanda constante. $\mathrm{O}$ acesso por meio do celular ou por site exclui uma grande parcela da população em situação de vulnerabilidade. Para os imigrantes, acrescenta-se também a barreira linguística e a própria falta de compreensão sobre a política de proteção social no Brasil e seus benefícios sociais, como o bolsa família, e a forma de acessá-los pelo Cadastro Único. Houve também demanda por atendimento jurídico para imigrantes que tiveram êxito na solicitação do auxílio, porém foram impedidos de retirar o recurso nas agências da Caixa Econômica Federal, por conta de não possuírem documentação brasileira, ou seja, carteira nacional de registro migratório (CRNM), ou pelo menos, o documento provisório de registro migratório (conhecido como protocolo).

Apesar de tais demandas representarem um recorte da situação da população imigrante dentro do cenário nacional, por ser deduzido a partir do atendimento aos imigrantes residentes em São Paulo, verificam-se dois gargalos estruturais nessa análise dos impactos da pandemia para a garantia de acesso a direitos e serviços públicos pela população imigrante. O primeiro deles é a falta de adaptação e investimento da política de proteção social para as especificidades da população imigrante. Apesar da lei de migração, publicada em 2017, deixar expresso no seu art. $4^{\circ}$, VIII, a garantia de acesso à população imigrante aos serviços de assistência social, a situação atual ainda está longe do ideal. No município de São Paulo, a quantidade de centros de acolhida para a população imigrante, por exemplo, é insuficiente para o número de imigrantes que chegam à cidade diariamente em busca de melhores condições de vida. Além disso, a dificuldade de integração econômica e social faz com que muitos imigrantes demorem até atingir 
autonomia financeira para buscar uma moradia autônoma, ou seja, os centros de acolhida servem de apoio não apenas para os recém-chega$\operatorname{dos}^{4}$.

Outro gargalo estrutural envolve todo ato referente ao processo de bancarização. A recusa em aceitar documentos válidos do país de origem como documentos de identidade ou até mesmo de não reconhecer o documento provisório de registro migratório (apesar da carta circular no 3.183/2017, expedida pelo Banco Central) demonstra a resistência e a falta de alinhamento por parte das instituições financeiras em oferecer os mesmos serviços ofertados aos brasileiros à população imigrante. Antes da pandemia, já era comum a dificuldade enfrentada pelos imigrantes em executar trâmites bancários básicos, como a simples abertura de conta.

Diante desse atual cenário de pandemia, diversos desafios se impõem na garantia de direitos da população imigrante no país. Porém, é importante não perder de vista quais problemas surgem em decorrência da pandemia e, por outro lado, quais problemas já existentes tomaram proporções maiores em razão do coronavírus. Os gargalos destacados nesse texto demonstram que dificuldades enfrentadas pelos imigrantes neste atual período de pandemia já estavam presentes no momento anterior, como obstáculos à integração social dessa população.

De qualquer forma, é inquestionável que a pandemia do coronavírus será um divisor de águas e impactará profundamente não apenas nossos hábitos sanitários e a forma de se relacionar uns com os outros, mas principalmente a economia e o mundo do trabalho. E, nesse sentido, é importante se discutir como os imigrantes irão se inserir

\footnotetext{
${ }^{4}$ Para aprofundamento da discussão sobre assistência, moradia e migração, ver: CORDEIRO, S.; DEFENDI, C. CRAI Ocupa: trabalho social com imigrantes em ocupações. In: III Congresso Internacional de Política Social e Serviço Social: Desafios Contemporâneos, UEL, 2019, Londrina Disponível em:: https://www.congressoservicosocialuel.com.br/trabalhos2019/assets/4604-227894-35393-2019-03-18-defendi \%2C-c--cordeiro\%2C-s._trabalho_eixo_-fluxos-migrat\%C3\%B3rios-e-pol $\% \mathrm{C} 3 \%$ ADticas-sociais-(uel).pdf
} 
nessa nova conjuntura dos próximos meses (e talvez anos), considerando que antes já eram sujeitos à extrema precarização laboral.

Mais do que nunca, os esforços exercidos por organizações da sociedade civil, coletivos de imigrantes, pesquisadores e atores públicos, em defesa da garantia dos direitos da população imigrante se farão necessários, não apenas para prover atendimento a essa população, mas para incidir politicamente em pautas relacionadas à pandemia e na implementação de medidas governamentais que levem em consideração as especificidades da população imigrante.

\section{Considerações finais}

A partir da identificação da situação enfrentada por imigrantes e refugiados no contexto internacional e no Brasil - particularmente no município de São Paulo -, foram tratadas, neste artigo, algumas "verdades da imigração" que se revelam no âmbito da crise provocada pela Covid-19. Além de evidenciarmos como há situações muito parecidas em diferentes partes do globo, que nos ajudam a entender tendências gerais colocadas aos imigrantes e refugiados - em especial ao trabalhador imigrante -, também oferecemos um registro histórico das demandas desse grupo social na cidade de São Paulo e uma análise dos gargalos estruturais para responder às urgências dessa população, acentuadas pelo atual contexto.

Para concluir, é preciso lembrar que mesmo em meio a dificuldades extremas, há espaço - no Brasil e em diversas outras partes do globo - para a reação dessa população, que busca permanentemente transformar sua realidade. Os imigrantes e refugiados lutam, apesar das dificuldades extremas ligadas à pandemia, para contrastar a invisibilidade, acessar direitos e sobreviver.

Se pensarmos o caso do Brasil, vale destacar a mobilização da rede de atenção ao imigrante, formada por diferentes atores como organizações da sociedade civil (Missão Paz, Sefras, ITTC, CDHIC, África do Coração, Presença da América Latina, Bibliaspa, entre outras), coletivos ( Sí, yo puedo, Base Warmis, Conviva Diferente etc) e o Po- 
der Público (como a Coordenação de Políticas para Imigrantes, o CRAI/SP e a Defensoria Pública da União). De forma articulada, buscam respostas para garantir o acesso dos imigrantes a direitos, combater a discriminação e a xenofobia e socorrer as necessidades urgentes (situação laboral, ajuda alimentar, reunião familiar, situação no isolamento, acesso aos benefícios sociais, impossibilidade de pagar aluguel, regularização dos indocumentados para receberem os auxílios). Nesse sentido, podemos citar o "tuitazo" pela regularização de imigrantes e refugiados; a distribuição pelo MST de marmitas solidárias e pães para imigrantes desempregados com produtos produzidos nos assentamentos; a tradução de materiais com informações sobre a Covid-19; a assistência jurídica da DPU; a campanha da Rede de Cuidados em Saúde para Imigrantes, dentre tantas outras iniciativas institucionais e de pessoas que atuam na linha de frente para socorrer a população imigrante neste contexto, mesmo com o alto risco de contraírem o vírus.

Há, portanto, muitas iniciativas sendo empreendidas em particular para mostrar que as medidas contra o coronavírus não devem ter distinção de nacionalidade ou situação migratória. Esse enfrentamento das barreiras nacionais, mesmo no contexto atual do mundo e do Brasil em que estas fronteiras são agressivamente reafirmadas, é um fenômeno que ganha importância vital nas lutas sociais sensíveis ao que Antunes (2018) defende: a necessidade de "se criar um novo modo de vida".

\section{Referências}

ANTUNES, R. O privilégio da servidão. São Paulo: Boitempo, 2018. AZEVEDO, R. Bolsonaro chama refugiados de "escória do mundo", Exame, 22 set. 2015.

BASSO, P. Imigração na Europa. In: ANTUNES, R. (Org). Riqueza e miséria do trabalho no Brasil II, São Paulo: Boitempo, 2013. 
. L'ascesa del razzismo nella crisi globale. In: BASSO, Pietro

(Org.). Razzismo di stato: Stati Uniti, Europa, Italia. Milano: FrancoAngeli, 2010. BASSO, Pietro; PEROCCO, Fabio (Orgs.). Gli immigrati in Europa: Diseguaglianze, razzismo, lotte. Milano: FrancoAngeli, 2003.

BASSO, P.; PEROCCO, F. (Orgs.) Gli immigrati in Europa: Diseguaglianze, razzismo, lotte. Milano: FrancoAngeli, 2003.

CONSTANT, A. F.; NOTTMEYER, O.; ZIMMERMANN, K. F. The economics of circular migration. In: CONSTANT, A. F.; ZIMMERMANN, K. F. (Eds.) International handbook on the Economics of Migration. Cheltenkam/Northampton: Edward Elgar Publishing, 2011.

CORDEIRO, S.; DEFENDI, C. CRAI Ocupa: trabalho social com imigrantes em ocupações. In: III Congresso Internacional de Política Social e Serviço Social: Desafios Contemporâneos, 2019, Anais Eletrônicos... UEL, 2019, Londrina Disponível em:: <https://www.congressoservicosocialuel.com.br/trabalhos2019/assets/4604-227894-353932019-03-18-defendi\%2C-c-cordeiro\%2C-s. trabalho eixo -fluxosmigrat $\% \mathrm{C} 3 \%$ B3rios-e-pol\%C3\%Adticas-sociais-(uel).pdf $>$. Acesso em 23 maio 2020

LANZA, L. M. et al. Imigrantes nos territórios: problematizações sobre intervenções profissionais nas políticas de seguridade social. Katál., v. 21, n. 2, maio/ago, 2018, 271-280.

MARTIN, M. Mais de 30.000 reais para escapar da Espanha de barco, El País, 25/04/2020. Disponível em: <https://brasil.elpais.com/brasil/ 2020-04-25/mais-de-30000-reais-para-escapar-da-espanha-de-barco.html.> Acesso em 23 maio 2020.

MONTOVANI, F.; FRAISSAT, Z. Colombianos dormem há dias no aeroporto de Guarulhos à espera de repatriação. Folha de São Paulo, 12/05/2020. Disponível em: <https://www1.folha.uol.com.br/mundo/ 2020/05/colombianos-dormem-ha-dias-no-aeroporto-de-guarulhosa-espera-de-repatriacao.shtml>. Acesso em 23 maio 2020. 
SANCHES, M. Coronavírus: nos EUA, cidades com migrantes brasileiros e hispânicos têm 30\% mais mortes por covid-19, BBC NEWS, 19/05/2020. Disponível em: <https://www.bbc.com/portuguese/internacional-52333349>. Acesso em 23 maio 2020.

SAYAD, A. A imigração ou os paradoxos da alteridade. São Paulo: Edusp, 1998.

ULLAH, A. Like sardines: Migrant workers suffering in Kuwait's desert detention camps. Middle East Eye, 15/05/2020. Disponível em < $\underline{\text { https:// }}$ www.middleeasteye.net/news/coronavirus-kuwait-migrant-workersbangladesh-detention-camps $>$. Acesso em 23 maio 2020.

VILLARREAL, M. Migrações na América Latina em tempo de coronavírus, Folha de São Paulo, 17/04/2020. Disponível em: < $\underline{\text { https:// }}$ www1.folha.uol.com.br/mundo/2020/04/migracoes-na-americalatina-em-tempo-de-coronavirus.shtml $>$. Acesso em 23 maio 2020. VILLEN, P. Direito ou concessão dos Estados? O debate sobre o fim do direito de refúgio. Comciência, Dossiê 216, 9 abr. 2020.

. (In)visíveis globais: imigração e trabalho no Brasil. São Paulo: Alameda, 2018. 
